\title{
Chapter 11 \\ Policing the Community Together: \\ The Impact of Technology on Citizen Engagement
}

\author{
Ben Brewster, Helen Gibson, and Mike Gunning
}

\section{Introduction}

At the core of engagement, and similarly the idea of 'community' as a whole, is the concept of social capital (Huysman and Wulf 2004). Social capital is a form of economic and cultural capital in which social interaction is vital, and in which social transactions are marked by cooperation, reciprocity and trust (Flora 1997), and where goods, services and interventions are produced in service of common goals. The concept of community policing is underlined by the exchange of social capital between the Police, other statutory and non-statutory organisations, citizens, communities and interest groups in pursuit of social cohesion and the collective efficacy that enables citizens and groups to participate in shaping the contexts and communities to which they belong and with whom they engage (Sampson and Raudenbush 1999). This exchange relies heavily on community participation, built upon trust and confidence in, and legitimacy of, those participating organisations and individuals. While the concepts of trust, confidence and legitimacy themselves are not inherently complex, they are values which are hard to foster, maintain and measure as the socio-political contexts and interactions that shape them are often multifaceted, fragile and sensitive to change.

The concept of community policing itself has been discussed as an extension of the 'social contract' that exists between police and citizens (van der Giessen et al. 2017), placing additional requirements and demands on both parties. From a policing perspective, this requires the acceptance of citizens and communities as a partner in local safety and security, and from the perspective of those citizens an acceptance of the police's role within their communities. But what is community

B. Brewster $(\bowtie) \cdot$ H. Gibson $\cdot$ M. Gunning

CENTRIC - Centre of Excellence in Terrorism, Resilience, Intelligence and Organised

Crime Research, Sheffield Hallam University, Sheffield, UK

e-mail: B.Brewster@shu.ac.uk; H.Gibson@shu.ac.uk; M.Gunning@shu.ac.uk 
policing? While the term is omnipresent in across western policing discourse, an agreed and accepted definition of what it actually entails remains elusive (Cordner 1998). Despite this continued ambiguity, the core philosophy of community policing, and thus a common thread across all of its contemporary manifestations, can be distilled to focus on those activities which seek to forge working partnerships between the police and communities (Peak and Glensor 1996).

While working in partnership with the community is a fundamental precept of community policing, actually forging and maintaining these relationships is a more complex and sensitive process than is often acknowledged. Different groups and communities are often so defined by the socio-cultural and socio-economic contexts that bring them together, meaning the requirements, in terms of enablers and barriers to successful collaboration, are disparate from one to the next, with no one-sizefits-all approach that can be implemented holistically. Moreover, community policing is a paradigm shift away from the normality of traditional police practice, meaning officers are often ill-equipped to overcome the unwillingness of communities' to work with them and foster the working relationships which are so fundamental to the success of the approach (Sarre 1997). Thus, the challenge of working with communities that are considered disadvantaged or maligned is further accentuated by these factors, requiring organisational and cultural changes to foster engagement with the public and ultimately empower communities to participate in efforts to tackle local crime-related problems (Cameron and Laycock 2002).

\section{Inclusion, Participation and Engagement}

Le Dantec (2016) conceptualises the idea of 'Publics'. That is a collective group of people who are enlisted by a common set of shared issues, values or ideals and the interventions being taken against them. In community policing, we can appropriate this concept of publics to refer to the disparate communities with which the core values and prerequisites for collaboration between them and the police are missing or underdeveloped. These groups, are so defined by the individuals, and individual contexts, that reside within them. While the term 'stakeholder' is often used to describe the individuals and groups with interests or concerns around a particular issue, here we move towards the use of implicated actors as a means of representing the balance of power, or lack of, that often exists within these contexts. These implicated actors are those individuals and communities who are physically present, but for whatever reason - and there can be many, are marginalised and/or silenced, and those who are not present physically - but are the targets of others' work (Le Dantec 2016).

Age, gender and socio-economic status can have huge implications when determining the factors that impact upon levels of social inclusion (Livingstone and Helsper 2007). These factors can have equally significant impacts upon the levels of digital inclusion, that is the individuals ability to access and use ICTs (particularly the internet) to do things that aid them day-to-day (Madon et al. 2009). The importance 
of digital inclusivity within the wider, more holistic concept of social inclusion only becomes transparent when we begin to consider how individuals from different contexts make appropriate use of ICTs to impact activities in their daily lives. Digital inclusion is not just a matter of access, but also one of capability, and whether the individual in question has the prerequisite skills to leverage the ICTs in question, and the knowledge of how and when to best make use of it (Faulkner and Kleif 2003; Thomas and Wyatt 2000) The concept of inclusion from a digital perspective goes beyond the notion of accessing resource, it extends to and is dependent upon the social relations that ICTs assist in the facilitation of.

\section{Technological Interventions for Community Participation and Engagement}

The use of the UNITY mobile app as a means of community engagement, the primary case study discussed later in this chapter, is far from the first instance of ICTs being used to bridge gaps between communities and the statutory and non-statutory organisations that offer support to particular problems. A prominent example comes from the 'National Ugly Mugs' (NUM) scheme ${ }^{1}$ designed to support sex workers in the UK. The scheme, born from the UK Network of Sex Projects, allows users, primarily sex-workers themselves, to anonymously report dangerous individuals that a believed to pose a risk or threat. Information reported through the scheme is then shared with other sex-workers. The same information is then passed on, providing the user consents, to the police. The project has been recorded as a success in both providing immediate protection to sex-workers and as a valuable resource to enrich the police's intelligence picture on crimes against them (Laing et al. 2013). Despite this, tensions between sex-workers and police remain high as sex-work remains illegal in the UK, despite widespread support for decriminalisation from some quarters (Grenfell et al. 2016). While the NUM scheme has been a relative success in circumventing the tradition of mistrust between the sex-work community and the police, there is still a visible divide between the two, and the reporting of violent and serious offences to the police by workers is still extremely patchy. This is often as a result of increases in law enforcement activity targeting the sex-work community, including raids on known premises and strict solicitation legislation that is present across some areas of the UK. Furthermore, the varied nature and scope of sex-work means the scheme is mostly used by indoor workers, with those engaging in street based solicitation, often considered to be some of the most at-risk individuals, missing out as a result of low levels of digital access, itself a consequence of their own socio-economic and socio-cultural precarity (Kinnell 2008).

Le Dantec (2016) also situates technological design interventions towards vulnerable communities, in this case around homelessness, and the relationship

\footnotetext{
${ }^{1}$ National Ugly Mugs scheme, https://uknswp.org/um/
} 
between the service providers and their clients (Le Dantec 2012), towards understanding the gulf between what is required for technological adoption, a process far beyond the provision of technological access (Le Dantec et al. 2011). Major events also often bring communities together, highlighting the need for cooperation and communication between different the stakeholders within them. In particular, events such as flooding, earthquakes and other disasters that directly affect specific communities and result in the displacement of people from their homes require effective communication to guide people towards assistance and support services. Although social media has been examined and heralded as a possible solution to this problem (Jin et al. 2011; Veil et al. 2011) the lack of a centralised service often makes the response somewhat disjointed. However, a community's resilience to disaster is often dependent on the strength of its existing social capital and thus embedding this capital before a disaster takes place is essential in fostering a more resilient response (McNulty and Rennick 2013).

Existing community engagement platforms include Nextdoor. ${ }^{2}$ Nextdoor is an online platform which brings geographic communities together to discuss local issues, as well as offering help, support and advice to those who ask for it. In the US, Nextdoor has already been touted as a community policing tool (Waddell 2016), providing a means where public agencies, not just the police, can register and contribute to local community issues. However, it has been noted that such a tool has the potential to amplify community tensions or heighten awareness of crime and thus increase fear. Privacy concerns also factor in people's use of the site. These concerns cover issues ranging from knowing when property is empty and thus vulnerable to robbery, to those surround data protection around how Nextdoor itself makes use of its users data (Masden et al. 2014). The Police have also debated the idea of using their own dedicated mobile application, but functions are often limited to accessing information around crime hotspots and local police information. Police-driven applications also suffer from their direct association with the police themselves. Their uptake is reliant on the presence of an existing culture of collaboration and participation within the communities using them. Moreover, in areas where these prerequisite relationships do not exist, users may fear being labelled as informants or have concerns about how their personal data may be used (Bullock 2017). Uptake in the use of these applications often reflects and even amplifies existing behaviours, cultural perceptions and trust relationships that communities have with the police. Community driven apps may be seen as having increased legitimacy compared to those imposed upon the public by statutory organisations. While the potential utility and value of mobile applications as a vector for participation and engagement across groups of implicated actors is clear and apparent, this should not be confused with any presumption that these mechanisms serve as a vehicle for enhanced participation and engagement. In fact, digital inclusion and participation do not necessarily reflect, or culminate in an increase in, the broader concept of social inclusion. In a study of homelessness in Edinburgh, Buré (2006) asserted that despite regular access to ICTs among the homeless population, the

${ }^{2}$ Nextdoor, https://nextdoor.com/ 
way in which they were being used actually contributed to a reinforcement of existing cultural practices and norms rather than acting as a mechanism, or vector, for change. Within these contexts, Le Dantec's (2016) proposition that "technological change stratifies us based on our willingness to incorporate it into our lives" holds true in that actors are perhaps more accurately classified based upon their use, rather than their access to ICTs. This use is more likely to reflect levels of overall social inclusion, rather than solely digital. A shared concern that underlies many of these applications is discerning, and ultimately fostering, the factors or drivers that actually encourage and motivate the implicated actors to which a particular intervention is targeting, to install an application or ICT and then to use it. That is, with technological access, technological adoption does not necessarily follow without some kind of 'hook' to encourage buy-in and drive voluntary uptake (Kvasny and Keil 2006).

\section{Technological Interventions for Community Policing: The UNITY Case Study}

In this section, we reflect upon the empirical experiences gleaned as a result of the 'UNITY' Project. ${ }^{3}$ UNITY sought to establish a framework for European best practice related to community policing, investigating the mechanisms needed to strengthen the connection between the police and the communities they serve, taking into account the divergent socio-cultural, economic and other factors that impact different communities across Europe. As one vehicle for engagement, UNITY developed ICTs to aid in bringing together the police, communities and other statutory and non-statutory organisations that may otherwise be disparate or operate in information silos. By doing this, and adhering to strict accessibility standards along the way, UNITY aimed to increase the social capital of participating communities, encourage engagement and participation from a diverse spectrum of organisations and community members, promote inclusion and then, as a consequence, enable them to become self-organising, solve their own problems and move from implicated actors to collective ones (Le Dantec 2016).

The notion that technology serves as a mechanism through which existing behaviours, patterns and practices are reinforced has been noted as evident to some extent in the pilot testing of the ICTs described in this paper. In areas where perceptions of trust with police were considered to be high already, and where there was existing precedent for collaboration, such as in Helsinki, Finland, tools were well received and levels of engagement were high. However, there was no evidence present in the feedback received that the tools themselves played a significant role in improving trust or levels of collaboration. The feedback received merely indicated that the tools provided acted as a vector through which existing norms and practices were

\footnotetext{
${ }^{3}$ http://cordis.europa.eu/project/rcn/194893_en.html
} 
transferred, reinforcing the observations of Buré (2006) in reference to homeless communities in Scotland.

As one component of the UNITY approach, a mobile app was developed as a means to bridge the gap between police, other statutory and non-statutory organisations, and the wider public. This technological intervention, sought to enhance participation and engagement between groups across 'six pillars' of activity. These pillars, abstracted and aligned to a contextualised representation of the activities contained with the Policing Activity Glossary (Robinson 2011) take into account the requirement to; (1) address local needs, (2) build trust and confidence with communities, (3) enhance collaboration, (4) prevent crime, (5) improve accountability and (6) facilitate effective communication. The Policing Activity Glossary was developed by the National Police Improvement Agency as a means to standardise that roles and responsibilities of police in the UK. The UNITY mobile application works seamlessly with a partner online web platform that provides an online interface to the functionalities available within the mobile app. The portal also provides additional information to LEAs and other elevated users, through the use of analytics related to the use and content of the portal (James et al. 2016).

The mobile application, deployed and tested against scenarios in Belgium and Finland, utilises basic functionalities such as a message-board, the ability to organise events and meetings, and a person-to-person direct messaging feature as mechanisms through which the ability of dedicated channels for citizens, community groups and police to act as a means to influence improved participation and engagement could be tested. Figure 11.1 shows a number of screens from the iOS version of the application. The screenshots show the login screen, core menu, direct message and news/events interface. The mobile app was designed to adhere to existing design and interface standards so as to ensure pilot testing participants were able to use it without prior training.

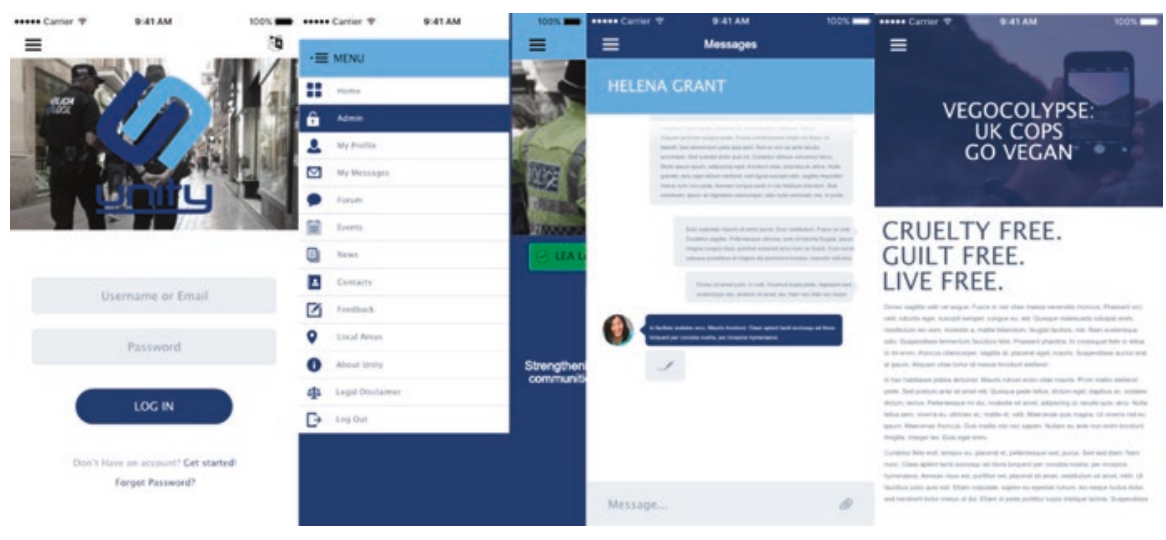

Fig. 11.1 UNITY mobile application 


\section{Validation and Discussion}

The developed mobile application was tested against a number of scenarios, defined by 'end-user' Police forces from Belgium and Finland. The scenarios themselves were designed to be indicative of real events, reflecting local needs in each location that had traditionally presented a unique challenge for police in terms of their relationships, communication and collaboration with the local community. The testing approach was built on the operational knowledge and experience of the police who operate at the test sites, from the identification of contextual issues and challenges in the communities they serve, through to the existing approaches used to engage with the communities and citizens in pursuit of a satisfactory resolution. The scenarios implemented were designed around events and activities that engage different communities and groups to reveal additional detail and insights about local issues that would otherwise remain hidden, at least partially, to the police and other statutory organisations. The pilot tested the mobile application against the six pillars of community policing identified earlier, across three primary application domains; (1) the reporting of community incidents, events and information by citizens, (2) the exchange of information between citizens, community groups and the police in order to improve community safety, (3) information flows from the police back to communities regarding specific issues and incidents.

The following section summarises the scenarios and the feedback gleaned as a result of the tests, focusing in particular on feedback discussing issues associated with the impact of the deployed mobile applications on community engagement in terms of its ability to enable community participation and the barriers that remain where it is implied that technology alone is unable to bridge the divide. Feedback was established through a number of mechanisms, including face-to-face interviews, debrief sessions and an online questionnaire. Participants included those from the communities and groups taking part as well as local police.

In Antwerp, Belgium, two scenarios were used to test different aspects of community policing in the area; police response and community communication. The first scenario was set around a large cinema complex where two cinemagoers had identified individuals behaving unusually near the complex. Using the mobile application, participants were able to discreetly photograph the area and the individuals concerned and report this to the cinema's private security who were also participating using the UNITY application. Cinema security were then able to liaise with the police who could subsequently notify nearby patrols; one of which was able to identify an individual in the photo. The police were then able to visit the address of the suspect who ascertain that the incident had been a misunderstanding. The role of UNITY in this situation was to give members of the public a safe reporting space for suspicious behaviour that may not warrant an emergency call but gives them an opportunity to 'do something'. This echoes current advice in the UK where campaigns such as 'See it. Say it. Sorted' from the British Transport Police ${ }^{4}$ and 'Action

\footnotetext{
${ }^{4}$ 'See It. Say It. Sorted.' How you can keep the Railway safe http://www.btp.police.uk/advice_ and_information/see_it_say_it_sorted.aspx
} 
Counters Terrorism' (ACT) $)^{5}$ encourage members of the public to report suspicious behaviour confidentially.

The second scenario concerned the Jewish community and how an attack in another country may contribute to raising tensions in the community. Following this incident, the police were able to reach out, through UNITY, to the local Jewish community to provide reassurance. However, during the process it came to light that an attack on the community may be imminent. Police were able to advise and communicate through Unity about any ongoing threats as well as receive information from the public. Eventually the threat subsided and due to the strong communication channels the community subsequently felt more engaged with the police in their local area. While on the surface, although in a controlled environment, the pilot test proved successful, from the police's perspective the influx of additional information actually posed problems in terms of resourcing and public expectation. As the UNITY platform, for the purposes of the test, represented an official channel for communication, police were actually worried it created expectations of response which were not always possible to meet, a problem which would need to be carefully mediated moving forward in order to avoid a backlash and a reduction in the trust relationships that led citizens and community groups to engage in the first place.

In Finland, two scenarios were used to test the application. The first used a shopping mall in Helsinki. The mall is question was situated by an area where it is perceived there is a high proportion of drug abuse, and is inhabited by marginalised groups, including a large migrant community. The mall itself is badly deteriorated and downtrodden. Police intelligence from the area suggested that illegal drugs were openly used in the near vicinity of the mall with drug paraphernalia, including used syringes visible in the nearby area. Drug addicts are known to peddle stolen goods in public and the aggressive collection of drug debts is also commonly seen. The area is seen as being hostile towards woman. The mall was selected due to these aforementioned problems which together create a complex policing problem. These problems are further exacerbated by the lack of communication and cohesion between the police and the local community. In some instances, there was no trust between the community, the police and mall management, in others trust existed, but no participation, and others there was participation but little in the way of reliable empirical knowledge about the problems that exist around the mall. In all cases, there lacked a common platform whereby discourse about these issues can be had between all parties.

The second scenario focused on a rural area to the north of Helsinki. The community has an unusual problem with the protected, but endangered, wolf population who visit residential areas and nearby farms causing danger to both small children and livestock. Due to their protected status, the situations with the wolves causes

\footnotetext{
${ }^{5}$ https://act.campaign.gov.uk/
} 
tensions with the hunting and farming community alike who have seen their desires to control the dwindling wolf population declined. This tense relationship means that crime often goes unreported in the area as the aforementioned groups do not want to be seen as cooperating with police among their peers.

In both locations, qualitative feedback indicated that the UNITY application provided a mechanism that reinforced existing relationships, where they existed, between communities and police. However, there was also feedback that indicated that, in situations where trust already existed that the additional value of using a bespoke, dedicated platform over existing mature fora such as Facebook and Twitter was not immediately clear. Local police in Tampere noted that; "there was another platform [which was] already developed, which could be potentially used for the same purpose. [The] UNITY tools should provide additional value". However, it is in one specific scenario, namely that related to the wolves in Finland that the platforms additional value was first alluded to. Police in Tampere stated that; "[the] discussion forum provided an official and moderated channel with restricting rules to discuss with the police about illegal hunting - so far there has not been such [a] forum. Discussion around the issue is very heated in the social media". It is here then, that the provision of a platform that provides assurance of anonymity, in cases where the user so desires, begins to add value. While anecdotal information from the pilot test suggested that dialogue on social media around the subject was abundant and heated, there lacked an official moderated mechanism where the community and the implicated actors within it could raise specific concerns and engage in dialogue with the police around local issues.

In terms of building trust and confidence within communities however, while the application provided a potentially valuable vector through which information can be shared and collaboration fostered, there is little evidence gleaned as a result of the test that suggests that the very presence of a mobile app in isolation actually provides a way through these obstacles. In the Finnish pilot local police in Tampere noted that the applications; "provided a potential platform for information sharing and collaboration for a group of stakeholders that had a low level of trust towards police". However, in Helsinki it was clearly noted by police there that trust was vital prerequisite for collaboration, and the reason for the high uptake and enthusiasm experienced was primarily due to high existing levels of confidence and trust in the police. Additionally, another user suggested they would prefer more clarity on which responses are attributed to police users within the forums. In Belgium, anecdotal information was received regarding the perceived appreciation from both of the communities and the police in terms of the application's ability to provide a means of direct communication with the other, however there was no suggestion that mobile app use was able to build trust and confidence, more that it reflected levels of trust and confidence that existed already - merely providing a new vector through existing behaviours could be observed. 


\section{Discussion and Further Work}

From the results and the overarching discussion presented in this paper, it is clear that ICTs have a role to play in the engagement between communities and police. However, to what extent these ICTs, if any, have in building relationships between these, often disparate, implicated actors remains clouded. The results of our work around community policing reinforce existing prepositions gleaned from the research and discourse around the homeless and sexworker communities, results which indicate that the use of ICTs as a means of fostering engagement and enhancing participation remains limited. Instead, in these contexts, ICTs mirror, and in some cases reinforce existing behaviours. In themelves, these behaviours reflect the underlying feelings of trust and accountability that individuals and communities have towards the police and other statutory organisations. While greater digital inclusion can be a vehicle for enhanced social inclusion, there is no evidence to suggest from the work presented here that it is a dependant factor, nor a sole means through which it can be fostered. Despite this, there remains significant scope for further study around ICT interventions in this and other domains. In particular those where there exists a culture of distrust, or little precedent of cooperation between community groups and statutory bodies, and in particular the police.

Acknowledgment The UNITY project received funding from the European Union's Horizon 2020 Programme for Research and Innovation under grant agreement no 653729. The authors would like to express their gratitude to the project consortium as a whole for their role in shaping and facilitating the pilots that test and continue to inform the development of the UNITY mobile application.

\section{References}

Bullock, K. (2017). The police use of social media: Transformation or normalisation? Social Policy and Society, 17, 1-14. https://doi.org/10.1017/S1474746417000112.

Buré, C. E. (2006). Digital inclusion without social inclusion: The consumption of Information and Communication Technologies (ICTs) in homeless subculture in Central Scotland. The Journal of Community Informatics, 2(2.) Retrieved from http://ci-journal.net/index.php/ciej/ article/view/251/212.

Cameron, M., \& Laycock, G. (2002). Crime prevention in Australia: Issues in policy and research. In A. Graycar \& P. Grabosky (Eds.), The Cambridge handbook of Australian criminology. Melbourne: Cambridge University Press. Retrieved from http://books.google.com/ books?hl=es\&lr=\&id=jU7vfyR7q_kC\&pgis=1.

Cordner, G. W. (1998). Community policing: Elements and effects. In G. Alpert \& A. Piquero (Eds.), Community policing: Contemporary readings. Illinois: Waveland Press.

Faulkner, W., \& Kleif, T. (2003). One size does not fit all! Digital in/exclusion in a rural community. SGGIS case study report. Edinburgh: University of Edinburgh.

Flora, C. (1997). Building social capital: The importance of entrepreneurial social infrastructure. Retrieved September 23, 2017, from http://dgroups.org/file2.axd/9cccfd87-46a6-4a00-80ab1224c6345443/Building_Social_Capital.doc 
van der Giessen, M., Brein, E., \& Jacobs, G. (2017). Community policing: The relevance of social contexts (pp. 35-50). https://doi.org/10.1007/978-3-319-53396-4_4

Grenfell, P., Eastham, J., Perry, G., \& Platt, L. (2016). Decriminalising sex work in the UK. BMJ, i4459. https://doi.org/10.1136/bmj.i4459.

Huysman, M., \& Wulf, V. (2004). Social capital and information technology: Current debates and research. Social capital \& information technology. Retrieved from http://books.google.com/ books?hl=en\&lr=\&id=8uYbB1 AeVrYC\&oi=fnd\&pg=PR7\&dq=Social+Capital+\&+Informat ion+Technology\&ots=AyDgtWDk0T\&sig=YOxm20lNHzN3tHd9IYqYTi6T8YU

James, D., van der Giessen, M., Bayerl, P. S., Jacobs, G., Karlovic, R., \& Markarian, G. (2016). Concept development of ICT tools and applications within the UNITY project. In J. Vukosav, K. Butorac, \& S. Joško (Eds.), Proceedings of the 5th international scientific and professional conference the police college research days in Zagreb new technologies and methods used for improvement of the police role in security matters Zagreb, Croatia,. Ministry of the Interior of the Republic of Croatia, Police Academy. Retrieved from https://www.mup.hr/ UserDocsImages/PA/vps/idvps_2016/docs/ZBORNIK_PROCEEDINGS_2016.pdf

Jin, Y., Liu, B. F., \& Austin, L. L. (2011). Examining the role of social media in effective crisis management: The effects of crisis origin, information form, and source on publics' crisis responses. Communication Research, 41(1), 74-94. https://doi.org/10.1177/0093650211423918.

Kinnell, H. (2008). Violence and sex work in Britain (p. 290). https://doi.org/10.4324/ 9781843926887

Kvasny, L., \& Keil, M. (2006). The challenges of redressing the digital divide: A tale of two US cities. Information Systems Journal, 16(1), 23-53. https://doi.org/10.1111/j.1365-2575.2006.00207.x.

Laing, M., Pitcher, J., \& Irving, W. A. (2013). National Ugly Mugs Pilot Scheme Evaluation Report. Retrieved from http://www.uknswp.org/wp-content/uploads/NUM Evaluation FIN 090813.pdf

Le Dantec, C. (2012). Participation and publics: Supporting community engagement. In CHI ' 12 Proceedings of the SIGCHI Conference on Human Factors in Computing Systems (pp. 13511360). https://doi.org/10.1145/2207676.2208593

Le Dantec, C. (2016). Designing publics. MIT Press. Cambridge, Massachusetts, USA.

Le Dantec, C., Farrell, R. G., Christensen, J. E., Bailey, M., Ellis, J. B., Kellogg, W. A., \& Edwards, W. K. (2011). Publics in practice: Ubiquitous computing at a shelter for homeless mothers. In Proceedings of the 2011 annual conference on Human factors in computing systems (pp. 16871696). https://doi.org/10.1145/1978942.1979189

Livingstone, S., \& Helsper, E. (2007). Gradations in digital inclusion: Children, young people and the digital divide. New Media \& Society, 9(4), 671-696.

Madon, S., Reinhard, N., Roode, D., \& Walsham, G. (2009). Digital inclusion projects in developing countries: Processes of institutionalisation. Information Technology for Development, 15(2), 95-107. https://doi.org/10.1002/itdj.20108.

Masden, C., Grevet, C., Grinter, R., Gilbert, E., \& Edwards, W. K. (2014). Tensions in scalingup community social media: A multi-neighborhood study of Nextdoor. In Proceedings of the 32nd annual ACM conference on human factors in computing systems (pp. 3239-3248). New York, NY: ACM. https://doi.org/10.1145/2556288.2557319.

McNulty, A., \& Rennick, K. (2013). The experience of flooding in the UK: A research study. British Red Cross. London: UK. (pp. 1-76).

Peak, K. J., \& Glensor, R. W. (1996). Community policing and problem solving: Strategies and practices (p. 436). Englewood Cliffs, NJ: Prentice Hall.

Robinson, O. (2011). Driving strategic IT through business architecture. In Innovate 2011: the rational software conference. Retrieved from ftp://ftp.software.ibm.com/software/uk/itsolutions/innovate/track02/SE3_Driving_Strategic_IT_Through_Business_Architecture.pdf

Sampson, R. J., \& Raudenbush, S. W. (1999). Systematic social observation of public spaces: A new look at disorder in urban neighborhoods. American Journal of Sociology, 105(3), 603-651. https://doi.org/10.1086/210356. 
Sarre, R. (1997). Crime prevention and police. In A. O'Malley \& A. Sutton (Eds.), Crime prevention in Australia: Issues in policy and research (p. 64). Leichhardt Federation Press. New South Wales, Australia.

Thomas, G., \& Wyatt, S. (2000). Access is not the only problem: Using and controlling the internet. In S. Wyatt, F. Henwoord, N. Miller, \& P. Senker (Eds.), Technology and in/equality. Questioning the information society (pp. 21-45). London: Routledge.

Veil, S. R., Buehner, T., \& Palenchar, M. J. (2011). A work-in-process literature review: Incorporating social media in risk and crisis communication. Journal of Contingencies and Crisis Management, 19(2), 110-122. https://doi.org/10.1111/j.1468-5973.2011.00639.x.

Waddell, K. (2016). The police officer "nextdoor." Retrieved from https://www.theatlantic.com/ technology/archive/2016/05/nextdoor-social-network-police-seattle/481164/

Open Access This chapter is licensed under the terms of the Creative Commons Attribution 4.0 International License (http://creativecommons.org/licenses/by/4.0/), which permits use, sharing, adaptation, distribution and reproduction in any medium or format, as long as you give appropriate credit to the original author(s) and the source, provide a link to the Creative Commons license and indicate if changes were made.

The images or other third party material in this chapter are included in the chapter's Creative Commons license, unless indicated otherwise in a credit line to the material. If material is not included in the chapter's Creative Commons license and your intended use is not permitted by statutory regulation or exceeds the permitted use, you will need to obtain permission directly from the copyright holder.

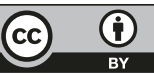

